17 Van Niel, C. B., in "Photosynthesis in Plants", edit. J. Franck and W. E. Loomis, 437 (Iowa State College Press, 1949)

${ }^{18}$ Fuller, R. C., Proc. Ninth Intern. Bot. Congr., 2, 125 (1959). ${ }^{19}$ Frenkel, A. W., J. Amer. Chem. Soc., 76, $5568(1954)$; J. Biol Chem.,
222, 823 (1956).

${ }^{20}$ Newton, J. W., and Kamen, M. D., Biochim. Biophys. Acta, 25, 462 (1957).

${ }^{21}$ Anderson, I. C., and Fuller, R. C., Arch. Biochem. Biophys., 78, 168 (1958).

${ }^{22}$ Fuller, R. C., and Anderson, I. C., Plant Physiol. (Supp.), 32, xvi $(1957)$

${ }^{23}$ Rosenberg, L. L., Capindale, J. B., and Whatley, F. R., Nature, $181,632(1958)$.

${ }^{24}$ Mortlock, R. P., Valentine, R. C., and Wolfe, R. S., J. Biol. Chem.,

${ }^{25}$ Sisler, E. C., and Fuller, R. C., Fed. Proc., 18, 1286 (1959).
${ }^{26}$ Losada, M., Trebst, A. V., Ogata, S., and Arnon, D. I. (in preparation). ${ }^{27}$ Lynen, F., and Decker, K., Ergebn. Physiol., 49, 327 (1957).

${ }^{28}$ Barker, H. A., Weissbach, H., and Smyth, R. D., Proc. U.S. Nat. Acad. Sei., 44, 1093 (1958).

${ }^{20}$ Glover, J., Kamen, M. D., and Van Genderen, H., Arch. Biochem. Biophys., 35, 384 (1952)

se Arnon, D. Y., in "Light and Life", edit. by MeElroy, W. 3., and Glass, i3. (Johns Hopkins Univ.' Press) (in the press).

${ }^{31}$ Maclachlan, G. A., and Porter, H. K., Proc. Roy. Soc., B, 150, 460 (1959).

${ }^{32}$ Benson, A. A., and Calvin, M., "Ann. Rev. Plant Physiol.", 1, 40 (1950).

ss Oparin, A. I., "The Origin of Life on the Earth", third ed. (Academic Press, New York, 1957).

${ }^{3 .}$ Priestley, J., "Experiments and Observations on Different Kinds of Air", 1, 49 (J. Johnson, London, 1774).

\title{
OBITUARIES
}

\section{Prof. W. E. Garner, C.B.E., F.R.S.}

THE news of the death of Prof. W. E. Garner at his home in Bristol on March 4 was received with much sadness by his former colleagues at the University of Bristol, and particularly by those who had the privilege of working with him and under his leadership.

Garner was a man of great charm and kindness who won the affection and admiration of all who came into contact with him. His unselfishness and sincerity made him the most likeable of men. He was quiet, unobtrusive, entirely devoid of personal ambition and devoted to his work, whether it be in his labora. tory, the councils of the University, or in the committee room. But these unassuming qualities did not obscure the greatness of the man. He was an enthusiastic and inspiring leader of research : keenly critical in scientific matters, yet very kindly and tolerant in his attitude to the ideas of others. Always most conscientious in the discharge of his duties, he maintained the tradition of lecturing to first-year students and he liked to know the students personally. The wide circle of friends, students and of many others who sought his advice and received it, valued a friend ship which will endure as a cherished memory of a lovable character.

Garner was a student of the University of Birmingham, where he carried out research with Prof. P. F Frankland. He was awarded an 1851 Exhibition in 1913 and proceeded to the University of Göttingen to work with Prof. Gustav Tammann. His work there was interrupted by the outbreak of the First World War, and on his return to England he worked at Woolwich Arsenal with Sir Robert Robertson on the calorimetry of high explosives.

On leaving Woolwich, Garner was appointed assistant lecturer in the University of Birmingham (January 1919) and assistant lecturer at University College, London (October 1919). From that time began a close and happy association with Prof. F. G. Donnan and a fruitful period of research.

In 1927, Garner was appointed to the Leverhulme chair of physical and inorganic chemistry in the University of Bristol, a post which he held until his retirement in 1955.

During the Second World War he established an extra-mural research team in the University of Bristol under the Ministry of Supply to assist Government ordnance factories in research on explosives and munitions. The group continued until the end of the War, although Garner himself moved to Fort
Halstead in Kent to become in turn superintendent of Chemical and Explosives Research, deputy chief. and later chief, superintendent of Armament Research in the Ministry of Supply. His wide knowledge. enthusiasm and wise guidance were of paramount importance to the war effort, and he was associated with many important developments in armaments and munitions. His services were recognized in 1946 when he was made C.B.E.

On the cessation of hostilities, Garner once again returned to Bristol and continued his fundamental researches with increasing vigour. $\mathrm{He}$ had a wide interest in, and keep knowledge of, many branches of physical chemistry, and his mental qualities were only fully employed when he was simultaneousiy. developing many research lines. Broadly, his main contributions to physical chemistry fall into the following groups : (a) The study of explosive reactions in gases and the ionization and radiation from flames : notable among these researches was the discovery of the effect of small amounts of hydrogen on the radiation from carbon monoxide flames. (b) Heterogeneous catalysis and particularly the measurements of heats of adsorption. $\mathrm{He}$ and his colleagues in Bristol made outstanding contributions to the mechanism of adsorption on metals and metallic: oxides, and he was a leader in applying the newer ideas of the physics of the solid state to the interpretation of heterogeneous reactions. (c) The kinetics of solid reactions. Garner's pioneering studies on the mechanism of the interface reactions and nucleation processes in solid reactions, and the development of suitable experimental techniques, constitute a chapter to the progress of a subject in which he was the acknowledged leader in Britain.

After his retirement in 1955 his continued interest in these topics and his freedom from other responsibilities enabled him to organize a symposium on chemisorption at Keele, Staffordshire, which was published by the Chemical Society, and to edit a large volume on the "Chemistry of the Solid State". Most of the contributors to the latter volume were his former students or close scientific colleagues, and the book is very much a tribute to his work and inspiration.

Garner was a well-known figure at scientific gatherings, and scientific societies and Government committees made great calls upon his time. He was president of the Faraday Society (1945-47); a member of the Scientific Advisory Council of the Ministry of Supply for most of the period 1942-60. and also a scientific advisor for civil defence in the south-west region of Britain. 
He received many honours: he was elected to the fellowship of the Royal Society in 1937; and was a Fellow of University College. He was well known abroad; he was an honorary member of the Polish Chemical Society, a corresponding member of the Patronato "Alfonso el Sabio", Madrid (1959), and a member of the Joint Services Mission to the United States and Canada in 1948.

\section{E. H. BAWN}

\section{Prof. A. J. H. Goodwin}

Astley John Hirlary Goodwin was born in Pietermaritzburg on December 27, 1900, and died on December 5, 1959, after a long illness. The son of Canon W. A. Goodwin, he was educated at St. John's College, Johannesburg, and at the University of Cambridge, where he graduated in archæology. At the age of twenty-three he joined the staff of the University of Cape Town, serving there until his death. He was appointed associate professor in 1954 in recognition of his academic achievements and original work.

From the sixties of the nineteenth century, collectors had amassed considerable quantities of stone implements from large numbers of sites in southern Africa. Goodwin, on his return from Cambridge, first applied his mind to the problem of the systematic classification and chronological arrangement of this material and soon realized the need for a terminology that would be more applicable to the southern African facts than the European one hitherto accepted. He envisaged a subdivision of the Stone Age into three--Earlier, Middle and Later-each of which embraced a number of cultures and their variations. Collaboration with van Riet Lowe and Neville Jones led to the foundations of South African. prehistoric classification being laid and to the elab. oration of conjoint ideas in "The Stone Age Cultures of South Africa,". This contained basic systematic descriptions and has been used as the foundation for prehistoric studies in both South and East Africa.

Goodwin stressed the need for a strictly scientific approach to field exploration and to the drawing of conclusions. His method of approach is to be found in his handbook entitled "Method in Prehistory". $\mathrm{His}$ own field-work was intensive and marked by meticulous accuracy of observation, whether it was concerned with the excavation of caves and shelters or with the examination of sequences of styles in rock engravings. Mainly undertaken within the confines of the Cape Province, his original field observations were supplemented by visits to many critical sites in other parts of Africa; and he excavated and studied important more recent archæological sites in Nigeria on the invitation of the Government of that country.

Goodwin's methodical and lively mind embraced many cultural interests and made him a good organizer. He took a leading part in founding the South African Archæological Society, was its secretary for a number of years, edited its Bulletin, and at the time of his death was its president. With A. L. du Toit he was enthusiastic in founding the Athenæum Trust, which provided a 'home' for the scientific and cultural societies, the headquarters of which are in Cape Town. For some years he served as the honorary general secretary of the Royal Society of South Africa and on its council and, again in the year of his death, was elected to its presidency. Whatever task of this nature he was called upon to perform, he carried it out with quiet unobtrusive natural efficioncy and forthrightness; what he had to say was said quietly, suecinetly and directly. Discussion with him was a pleasure, but acrimonious discussion was impossible. To all those who had contact with him he was "John".

Our late colleague is survived by his widow, a son and a daughter. $\quad$ S. H. HadGhtoN

\section{Prof. C. J. Bakker}

Prof. C. J. BAKKER, whose death in an aeroplane accident in New York occurred on April 23, was on his way to attend a meeting of the American Physical Society in Washington. He had been invited to address the Society on recent researches at CERN and particularly on the successful operation of the 25-GeV. proton synchrotron.

Cornelis Jan Bakker was born in 1904 and studied physics under Zeeman in Amsterdam. After taking his doctorate (cum laude) in 1931 for original research on the Zeeman effect in the spectra of the noble gases, he spent a year in London at the Imperial College of Science and Technology continuing his work in spectroscopy. In the following year he joined the scientific staff of Philips, Eindhoven, where he worked on the physical problems of radio communications. His interests soon turned to nuclear physics and during the War, in collaboration with Prof. Heyn, he designed the Philips cyclotron. In 1946, he succeeded Gorter as professor of physics and director of the Zeeman. Laboratory of the University of Amsterdam. $\mathrm{He}$ also became director of the Institute of Nuclear Physics, the focal point of Dutch nuclear research sponsored by Fundamental Onderzoek der Materie, by the City of Amsterdam and by Philips. He was a member of the Royal Netherlands Academy of Sciences.

In 1951, Prof. Bakker was invited by Prof. Auger, director of the Unesco Department of Natural Science, to be one of the eight experts charged with drawing up plans for the future European Organization for Nuclear Research (CERN).

At the first session of the Council of CERN during May 5-8, 1952, Prof, Bakker was appointed a member of the directorate and director of the SynchroCyclotron Division. On July 1, 1955, he became deputy director-general of CERN, succeeding Prof. Felix Bloch as director-general on September 1, 1955.

During the years 1955-60 CERN has grown from an idea put forward by a few European scientists to one of the best-equipped laboratories for high-energy nuclear physies research in the world. In 1957 the CERN $600-\mathrm{MeV}$. synchro-cyclotron was commissioned, and since that time it has been in full use as a nuclear physies research tool. More recently, at the end of 1959 , the $25-\mathrm{GeV}$. proton-synchrotron came into operation at CERN.

In June 1957, Prof. Bakker received an honorary doctorate from the University of Geneva, and in April 1960 the Queen of the Netherlands awarded him the high honour of "Ridder in de orde van de Nederlandse Leeuw". His death took place before the official ceremony at which this award was to have been given.

Prof. Bakker believed firmly in European collaboration in science, and CERN, which is a unique and successful example of such collaboration, was inspired by his devoted leadership. His sudden death is a tragic loss to his wife and children, to CERN and to international scientific collaboration.

J. B. Anams 